\title{
The Diffusion Model of Grown-In Microdefects Formation During Crystallization of Dislocation-Free Silicon Single Crystals
}

\author{
V. I. Talanin and I. E. Talanin \\ Classic Private University \\ Ukraine
}

\section{Introduction}

Dislocation-free silicon single crystals are the basic material of microelectronics and nanoelectronics. Physical properties of semiconductor silicon are determined by the structural perfection of the crystals grown by the Czochralski and float-zone processes (Huff, 2002). In such crystals during their growth are formed grown-in microdefects.

Grown-in microdefects degrade the electronic properties of microdevices fabricated on silicon wafers. Optimizing the number and size of grown-in microdefects is crucial to improving processing yield of microelectronic devices. Many of the advances in integratedcircuit manufacturing achieved in recent years would not have been possible without parallel advances in silicon-crystal quality and defect engineering (Yang et al., 2009). The problem of defect formation in dislocation-free silicon single crystals during their growth is a fundamental problem of physics and chemistry of silicon. In particular it is the key to solving the problem engineering applications of silicon crystals. This is connected with the transformation grown-in microdefects during the technological treatment of silicon monocrystals.

Formation of grown-in microdefects occurs as a result of the interaction of point defects during crystal cooling. The distribution of grown-in microdefects in a growing crystal is influenced by its temperature field and the boundary conditions defined by its surfaces. Until recently it was assumed that the formation of grown-in microdefects is due to condensation of intrinsic point defects (Voronkov et. al., 2011). Recombination-diffusion model assumes fast recombination of intrinsic point defects at the initial moment of cooling the grown crystal. Fast recombination determines the type of dominant intrinsic point defects in the crystal. In this model was first used mathematical tool which allows you to associate the defect structure of crystal with distribution in the crystal thermal fields during the growth (Prostomolotov et al., 2011). It has been suggested that the fast recombination of intrinsic point defects near the crystallization front as a function of the growth parameter $V_{g} / G$ (where $V_{g}$ is the rate of crystal growth; $G$ is the axial temperature gradient) leads to the formation of microvoids or interstitial dislocation loops (Voronkov, 2008). It is assumed that in the case $V_{g} / G<\xi_{\text {crit }}$ formed only interstitial A-microdefects as a result of aggregation of intrinsic interstitial silicon atoms. It is assumed that in the case $V_{g} / G>\xi_{\text {crit }}$ formed only 
microvoids as a result of aggregation of vacancies (Goethem et al., 2008; Kulkarni, 2008a). In this physical model, the interaction between the impurities and intrinsic point defects is not considered (Kulkarni et. al., 2004).

Recent versions of this model have suggested that part of the vacancies (v) in the temperature range $1683 \ldots 1373 \mathrm{~K}$, due to the interaction with oxygen $(\mathrm{O})$ and nitrogen $(\mathrm{N})$ impurities, are bound into complexes of the $\mathrm{vO}, \mathrm{vO}_{2}$, and $\mathrm{vN}$ types (Kulkarni 2007; 2008b). After the formation of microvoids, the aforementioned complexes grow and take up vacancies. This model has ignored the growth of the complexes by means of the injection of intrinsic interstitial silicon atoms and the interaction of an impurity with intrinsic interstitial silicon atoms (Kulkarni 2007; 2008b).

In the general case recombination-diffusion model assumes that the process of defect formation in dislocation-free silicon single crystals occurs in four stages: (i) fast recombination of intrinsic point defects near the crystallization front; (ii) the formation in the narrow temperature range $1423 \ldots 1223 \mathrm{~K}$ depending on the value of $\mathrm{V}_{\mathrm{g}} / \mathrm{G}$ microvoids or interstitial dislocation loops; (iii) the formation of oxygen clusters in the temperature range $1223 . . .1023 \mathrm{~K}$; (iv) growth of precipitates as a result of subsequent heat treatments.

Recombination-diffusion model is the physical basis for models of the dynamics of point defects. The mathematical model of point defect dynamics in silicon quantitatively explains the homogeneous mechanism of formation of microvoids and dislocation loops. It should be noted that, in the general case, the model of point defect dynamics includes three approximations: rigorous, simplified, and discrete-continuum approaches (Sinno, 1999; Dornberger et. al., 2001; Wang \& Brown, 2001; Kulkarni et. al., 2004; Kulkarni, 2005; Prostomolotov \& Verezub, 2009). The rigorous model requires the solution to integrodifferential equations for point defect concentration fields, and the distribution of grown-in microdefects in this model is a function of the coordinates, the time, and the time of evolution of the size distribution of microdefects. A high consumption of time and cost for the performance of calculations required the development of a simplified model in which the average defect radius is approximated by the square root of the average defect area. This approximation is taken into account in the additional variable, which is proportional to the total area of the defect surface. The simplified model is effective for calculating the twodimensional distribution of grown-in microdefects. Both models use the classical nucleation theory and suggest the calculation of the formation of stable nuclei and the kinetics of diffusion-limited growth of defects. The discrete-continuum approximation suggests a complex approach: the solution to discrete equations for the smallest defects and the solution to the Fokker-Planck equation for large-sized defects.

Recently, we proposed a new model for the formation grown-in microdefects. The physical model of the formation of grown-in microdefects assumes that the defect formation in dislocation-free Si single crystals upon cooling occurs in three stages: (i) the formation of impurity aggregates near the crystallization front, (ii) the formation and growth of impurity precipitates upon cooling from the crystallization temperature, and (iii) the formation of microvoids or dislocation loops (depending on the growth parameter $V_{g} / G$ ) - in a narrow temperature range of $1423 . . .1223$ K (V.I. Talanin \& I.E. Talanin, 2006a; V.I. Talanin \& I.E. Talanin, 2010b). This model on the experimentally and theoretically established fact the absence of recombination of intrinsic point defects near the crystallization front of the crystal 
is based (V.I. Talanin \& I.E. Talanin, 2006a; V.I. Talanin \& I.E. Talanin, 2007a).With the help of the diffusion model of formation grown-in microdefects was calculated process of hightemperature precipitation (V.I. Talanin \& I.E. Talanin, 2010a). The processes of formation and growth of precipitates during cooling of the crystal is a controlling stage in the formation of the grown-in defect structure of dislocation-free silicon single crystals. At this stage, the formation and growth of oxygen and carbon precipitates occur in the temperature range from 1682 to 1423 K (V.I. Talanin \& I.E. Talanin, 2010a).

The mathematical model of point defect dynamics can be adequately used on the basis of the physical model in which the impurity precipitation process occurs before the formation of microvoids or dislocation loops (V.I. Talanin \& I.E. Talanin, 2010b). The model of point defect dynamics can be considered as component of the diffusion model for formation grown-in microdefects.

The aim of this paper is to present a diffusion model of formation grown-in microdefects in general and to discuss the possibility of its use as a tool for building the defect structure of dislocation-free silicon single crystal and device structures based on them.

\section{Classification of grown-in microdefects}

Currently, there are three classifications of grown-in microdefects: experimental classification, technological classification and physical classification.

Experimental classification of grown-in microdefects is based on the use of methods of selective etching, X-ray topography and transmission electron microscopy (Kock, 1970; Petroff \& Kock, 1975; Foll \& Kolbesen, 1975; Veselovskaya et al., 1977; Sitnikova et al., 1984; Sitnikova at al., 1985). A.J.R. de Kock entered the name of A-microdefects and Bmicrodefects, whereas E.G. Sheikhet entered the name C-microdefects, D-microdefects. We are entered the name (I+V)-microdefects (V.I.Talanin et al., 2002a, 2002b). These research allowed to establish the physical nature of A-microdefects, B-microdefects, C-microdefects, D-microdefects and $(\mathrm{I}+\mathrm{V})$-microdefects. Experimental results indicated the identity of the processes of defect formation in crystals of FZ-Si and CZ-Si (Kock et al., 1979; V.I. Talanin \& I.E. Talanin, 2003). This means that the classifications of grown-in microdefects in both types of crystals should also be identical (V.I. Talanin \& I.E. Talanin, 2004).

Technological classification is used for large-scale crystals. The larger the diameter of the growing crystal, the lower growth rate, at which the same type of grown-in microdefects is formed. This occurs by reducing the axial temperature gradient in the crystal (Ammon et al., 1999). This leads to the appearance of a new type of grown-in microdefects (microvoids) and dislocation-free crystal growth in a narrow range of growth rates (Voronkov \& Falster, 1998). In large crystals of interstitial dislocation loops and microvoids are considered as major grown-in microdefects in dislocation-free silicon crystals (Kulkarni et al., 2004).

Analysis of the experimental results of investigations of grown-in microdefects indicates that there are only three types of grown-in microdefects: precipitates of impurities $((\mathrm{I}+\mathrm{V})-$ microdefects, D(C)-microdefects, B-microdefects), dislocation loops (A-microdefects) and microvoids (V.I. Talanin et. al., 2011b). We established that the basic elements of defect formation are primary oxygen-vacancy and carbon-interstitial agglomerates, which are formed at impurity centers near the crystallization front (V.I. Talanin \& I.E. Talanin, 2006a). 
An excess concentration of intrinsic point defects (vacancies or silicon self-interstitials) arises when the crystal is cooled under certain thermal conditions (Cho et al., 2006). This process leads to the formation of secondary grown-in microdefects (A-microdefects or microvoids) (V.I. Talanin \& I.E. Talanin, 2004). We have proposed the physical classification of grown-in microdefects. It is based on the differences in the physical nature of the formation of primary and secondary grown-in microdefects (V.I. Talanin \& I.E. Talanin, 2006a).

\section{The diffusion model for formation of grown-in microdefects in dislocation- free silicon single crystals}

We propose a new diffusion model of the formation and transformation of grown-in microdefects. It is based on the experimental studies of undoped dislocation-free Si single crystals grown by the floating zone and Czochralski methods. The diffusion model combines the physical model (the heterogeneous mechanism for the formation of grown-in microdefects), the physical classification of grown-in microdefects, and mathematical models of the formation of primary and secondary grown-in microdefects (Fig. 1).

Physical model based on the assumption about the absence of recombination intrinsic point defects at high temperatures. This assumption was confirmed in several experimental works (Talanin et al., 2002a; Talanin et al., 2002b; Talanin et al., 2003). In paper (V.I. Talanin \& I.E. Talanin, 2007a) we first theoretically proved the absence of recombination of intrinsic point defects at high temperatures and fast recombination at low temperatures. The experimental data and the results obtained from thermodynamic calculations have demonstrated that the process of aggregation of point defects dominates over the process of recombination of intrinsic point defects. At high temperatures, the process of recombination makes an insignificant contribution to the process of aggregation. Consequently, vacancies and intrinsic interstitial atoms coexist in thermal equilibrium. As a result, intrinsic point defects of both types are simultaneously involved in the process of aggregation. The decomposition of a supersaturated solid solution of point defects occurs upon cooling through two mechanisms, namely, the vacancy and interstitial mechanisms, with the formation of oxygen-vacancy and carbon- interstitial agglomerates.

Absence of recombination intrinsic point defects at high temperatures allows us to propose the physical model of the formation grown-in microdefects. The basic concepts of the physics model for the formation of grown-in microdefects imply the following (V.I. Talanin \& I.E. Talanin, 2006a): (i) the recombination of intrinsic point defects at high temperatures can be neglected; (ii) background carbon and oxygen impurities are involved in the defect formation as nucleation centers; (iii) the decay of the supersaturated solid solution of point defects when the crystal is cooled from the crystallization temperature occurs in two independent ways (branches): vacancy and interstitial; (iv) the defect formation is based on primary agglomerates formed as the crystal is cooled from the crystallization temperature due to the interaction between the impurities and intrinsic point defects; (v) when the crystal is cooled at temperatures below $1423 \mathrm{~K}$, depending on the thermal growth conditions, secondary grown-in microdefects are formed due to the interaction between intrinsic point defects; (vi) the secondary grown-in microdefects are formed due to the coagulation (microvoids and A-microdefects) and deformation (A-microdefects) effects; (vii) the vacancy and interstitial branches of the heterogeneous mechanism have a symmetry, which implies simultaneous processes of defect formation during the decay of 
supersaturated solid solution of point defects; and (viii) the consequence of this symmetry is the formation of vacancy and interstitial grown-in microdefects of the same type and, correspondingly, the growth of dislocation-free Si single crystals in the same vacancyinterstitial mode (V.I. Talanin \& I.E. Talanin, 2006b). It was revealed that the growth parameter $V_{g} / G=\xi_{\text {crit }}$ describes the conditions under which the (111) face appears on the crystallization front (V.I. Talanin \& I.E. Talanin, 2006a). On the basis of physical model and concepts of primary and secondary grown-in microdefects we developed of physical classification of the grown-in microdefects (V.I. Talanin \& I.E. Talanin, 2006a).

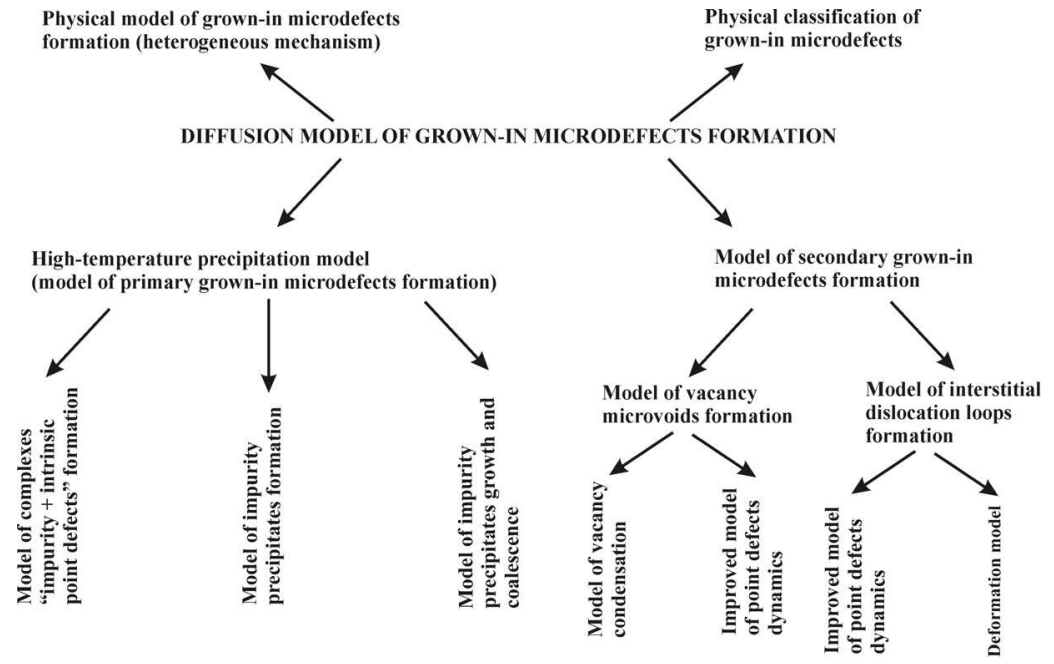

Fig. 1. Diffusion model of grown-in microdefects formation

A detailed description of the heterogeneous mechanism formation of grown-in microdefects and its correspondence to the results of experimental researches are presented in the articles (V.I. Talanin \& I.E. Talanin, 2004; V.I. Talanin \& I.E. Talanin, 2006a).

\section{Diffusion kinetic of high-temperature precipitation}

The calculation of the precipitation is carried out within the framework of the classical theory of nucleation, growth and coalescence of precipitates. For the calculation of formation and growth of precipitates are used analytic and approximate calculations. In the case of analytical calculations applied solution of differential equations of the dissociative diffusion (Talanin et al., 2007b, 2008). In the case of approximate calculations, the solution is sought in the form of systems of interconnected discrete differential equations of quasi-chemical reactions to describe the initial stages of nucleation of new phases and a similar system of continuous differential equations of the Fokker-Planck (V.I. Talanin \& I.E. Talanin, 2010a).

\subsection{Model of formation complex "impurity + intrinsic point defect"}

The solution is sought within the model of dissociative diffusion-migration of impurities (Bulyarskii \& Fistul', 1997). In this case, the difference from the decomposition phenomenon 
is that during diffusion (as a technological process), a diffusant is supplied to the sample from an external source, whereas in the case of decomposition it is produced by an internal source (lattice sites).

Vas'kin \& Uskov are considered the problem of successive diffusion of a component $A$ into a sample singly doped with a component $B$, taking into account the complex formation at the initial and boundary conditions (Vas'kin \& Uskov, 1968). We are conducted similar consideration for our conditions (Talanin et al., 2007b; 2008). Under physical-model conditions (heterogeneous mechanism of grown-in microdefect formation), we assume that the component $A$ is the background impurity (oxygen $O$ or carbon $C$ ) and the component $B$ is intrinsic point defects (vacancies $V$ or interstitials $I$ ). For the vacancy and interstitial mechanisms, we consider, respectively, the oxygen+vacancy $(O+V)$ and carbon+interstitial $(C+I)$ interactions. The calculations performed in the framework of approximation of strong complex formation have demonstrated that the edge of the reaction front of the formation of a complex (i.e., the "oxygen+vacancy" and "carbon + self-interstitials" complex) is located at a distance of $\sim 3 \cdot 10^{-4} \mathrm{~mm}$ from the crystallization front (Talanin et al., 2007b). We have shown that complex formation occurs near the crystallization front. Detailed calculations are presented in the articles (Talanin et al., 2007b, 2008).

\subsection{Model for the formation of precipitates}

Let us consider a system of a growing undoped dislocation-free silicon single crystal. The concentrations of all point defects at the crystallization front are assumed to be equilibrium, and both the vacancies and the intrinsic interstitial silicon atoms are present in comparable concentrations. During cooling of the crystal after passing through the diffusion zone, an excessive (nonequilibrium) concentration of intrinsic point defects appears. Excess intrinsic point defects disappear on sinks whose role in this process is played by uncontrollable (background) impurities of oxygen and carbon (V.I. Talanin \& I.E. Talanin, 2006a). In real silicon crystals, the concentrations of carbon and oxygen impurities are higher than the concentrations of the intrinsic point defects. The formation of complexes between the intrinsic point defects and impurities is governed, on the one hand, by the fact that both the intrinsic point defects and the impurities are sources of internal stresses in the lattice (elastic interaction) and, on the other hand, by the Coulomb interaction between them (provided the defects and the impurities are present in the charged state). The mathematical model under consideration allows for the elastic interaction and the absence of the recombination of intrinsic point defects in the high-temperature range (V.I. Talanin \& I.E. Talanin, 2007a). The concentrations of intrinsic point defects $C_{i, v}(r, t)$ in the growing crystal satisfy the diffusion equation $\partial C_{i, v} / \partial t=D_{i, v} \Delta\left(C_{i, v}-C_{i e, v e}\right)$ where $r$ is the coordinate and $t$ is the time. In the vicinity of the sinks (oxygen and carbon atoms), the concentration of intrinsic point defects $C_{i e, v e}$ is kept equilibrium, whereas the diffusion coefficients $D_{i, v}$ and the concentrations $C_{i e, v e}$ of intrinsic point defects decrease exponentially with decreasing temperature. Under these conditions, the formation of microvoids and interstitial dislocation loops is possible only at significant supersaturations of intrinsic point defects, which take place at a temperature $T=T_{m}-300 \mathrm{~K}$ (where $T_{m}$ is the crystallization temperature). For the formation of precipitates in the high-temperature range $T \sim 1683 \ldots 1403 \mathrm{~K}$ has been calculated using 
the model of dissociative diffusion (Talanin et al., 2007b; 2008). This approximation is valid at the initial stages of the formation of nuclei, when their sizes are small and the use of Fokker-Planck continuity differential equations is impossible. The calculations performed in the framework of this approximation have demonstrated that the edge of the reaction front of the formation of a complex is located at a distance of $\sim 3 \cdot 10^{-4} \mathrm{~mm}$ from the crystallization front. This spacing represents a diffusion layer in which an excessive concentration of intrinsic point defects appears.

We have considered the modern approach based on solving systems of coupled discrete differential equations of quasi-chemical reactions for the description of the initial stages of the formation of nuclei of new phases and a similar system of Fokker-Planck continuity differential equations.

In order to describe the kinetics of the simultaneous nucleation and growth (dissolution) of a new phase particles of several types in a supersaturated solid solution of an impurity in silicon was considered a system consisting of oxygen and carbon atoms, vacancies, and intrinsic interstitial silicon atoms. The interaction in this system during cooling of the crystal from $1683 \mathrm{~K}$ results in the formation of oxygen and carbon precipitates. In order to perform the computational experiments and to interpret their results was conducted a dimensional analysis of the kinetic equations and the conservation laws with the use of characteristic time constants and critical sizes of defects. This is made it possible to perform a comparative analysis of the joint evolution of oxygen and carbon precipitates and to optimize the computational algorithm for the numerical solution of the equations.

For example, for the case of a thin plane-parallel crystal plate of a large diameter, when the conditions in the plane parallel to the surface of the crystal can be considered to be uniform and the diffusion can be treated only along the normal to the surface (the $\mathrm{z}$ coordinate axis), the mass balance of point defects in the crystal is described by the system of diffusion equations for intrinsic interstitial silicon atoms, oxygen atoms, carbon atoms, and vacancies:

$$
\begin{aligned}
& \frac{\partial C_{o}}{\partial t}=D_{o} \frac{\partial^{2} C_{o}}{\partial z^{2}}-\frac{\partial C_{o}^{S i O_{2}}}{\partial t} \\
& \frac{\partial C_{c}}{\partial t}=D_{c} \frac{\partial^{2} C_{c}}{\partial z^{2}}-\frac{\partial C_{c}^{S i C}}{\partial t} \\
& \frac{\partial C_{i}}{\partial t}=D_{i} \frac{\partial^{2} C_{i}}{\partial z^{2}}+\frac{\partial C_{i}^{S i O_{2}}}{\partial t}-\frac{\partial C_{i}^{S i C}}{\partial t} \\
& \frac{\partial C_{v}}{\partial t}=D_{v} \frac{\partial^{2} C_{v}}{\partial z^{2}}-\frac{\partial C_{v}^{S i O_{2}}}{\partial t}+\frac{\partial C_{v}^{S i C}}{\partial t}
\end{aligned}
$$

where $C_{o}, C_{c}, C_{i}, C_{v}$ are the concentrations of oxygen, carbon, self-interstitials and vacancies respectively; $D_{o}, D_{c}, D_{i}, D_{v}$ are the diffusion coefficients of oxygen, carbon, self-interstitials and vacancies respectively.

In the system of equations (1), we took into account that the oxygen precipitates serves as sinks for oxygen atoms and vacancies and as sources of interstitial silicon atoms. At the same time, the carbon precipitates, in turn, also serve as sinks for carbon atoms and interstitial silicon atoms and as sources for vacancies. Kinetic model of decomposition of 
solid solutions of oxygen and carbon impurities not only allows one to simulate the processes of precipitation during cooling of the as-grown silicon crystal to a temperature of $300 \mathrm{~K}$ but also adequately describes the available experimental data on the oxygen and carbon precipitation (V.I. Talanin \& I.E. Talanin, 2011a).

The algorithm used for solving the problem of simulation of the simultaneous growth and dissolution of the oxygen and carbon precipitates due to the interaction of point defects during cooling of the crystal from the crystallization temperature is based on the monotonic explicit difference scheme of the first-order accuracy as applied to the Fokker-Planck equations.

Detailed calculations are presented in the articles (V.I. Talanin \& I.E. Talanin, 2010a). These calculations demonstrate that intrinsic point defects (vacancies and intrinsic interstitial silicon atoms) exert a significant influence on the dynamics of mass exchange and mass transfer of point defects between the oxygen and carbon precipitates. The absorption of vacancies by the growing oxygen precipitates leads to the emission of silicon atoms into interstitial positions. The intrinsic interstitial silicon atoms, in turn, interact with the growing carbon precipitates, which, in the process of growth, supply vacancies for growing oxygen precipitates. This interaction leads to such a situation that, first, the growth of the precipitates is suppressed more weakly because of the slower increase in the supersaturation of the intrinsic point defects in the bulk of the growing crystal and, second, the critical radius of the formation of carbon precipitates increases more slowly, which favors a more rapid growth of the carbon precipitates. The higher rate of the evolution of the size distribution function for carbon precipitates can be associated with the higher mobility of interstitial silicon atoms as compared to vacancies in the high-temperature range. It can be assumed that the mutual formation and growth of oxygen and carbon precipitates result in a lower rate of the evolution of the size distribution function of the oxygen precipitates, regardless of their smaller critical size at the initial instant of time, owing to the effect of the carbon impurity.

\subsection{Model of growth and coalescence of precipitates}

In the classical theory of nucleation and growth of new-phase particles, the process of precipitation in a crystal is treated as a first-order phase transition and the kinetics of this process is divided into three stages: the formation of new-phase nuclei, the growth of clusters, and the coalescence stage. At the second stage of the precipitation process, clusters grow without a change in their number. At the third stage of the precipitation process, when the particles of the new phase are sufficiently large, the supersaturation is relatively low, new particles are not formed and the decisive role is played by the coalescence, which is accompanied by the dissolution of small-sized particles and the growth of large-sized particles. The condition providing for changeover to the coalescence stage is the ratio $u(t)=R(t) / R_{c r}(t) \approx 1$, where $R_{c r}(t)$ is the critical radius of the precipitate.

Detailed calculations stages of the growth and the coalescence are presented in the article (V.I. Talanin \& I.E. Talanin, 2011a). The analysis was carried out under the assumption that precipitates grow at a fixed number of nucleation centers according to the diffusion mechanism of growth. The model corresponds to the precipitation uniform in the volume. An analysis of the results obtained and the data taken from (Talanin et al., 2007b; V.I. 
Talanin \& I.E. Talanin, 2010a) has demonstrated that the phase transition occurs according to the mechanism of nucleation and growth of a new phase so that these two processes are not separated in time and proceed in parallel.

The condition providing changeover to the stage of the coalescence is written in the form $R(t) \approx R_{c r}(t)$, which is satisfied for large-sized crystals at the temperature $\mathrm{T} \approx 1423 \mathrm{~K}$. Taking into account the computational errors, this temperature for large-sized crystals corresponds to the initial point of the range of the formation of microvoids (at $V_{g}=0.6 \mathrm{~mm} / \mathrm{min}$ ). In this range, all impurities are bound and there arises a supersaturation with respect to vacancies, which is removed as a result of the formation of microvoids. With a change in the thermal conditions of the growth (for example, at $V_{g}=0.3 \mathrm{~mm} / \mathrm{min}$ ), there arises a supersaturation with respect to interstitial silicon atoms, which leads to the formation of dislocation loops. In this case, the condition $R(t) \approx R_{c r}(t)$ is satisfied at $T \approx 1418 \mathrm{~K}$. Consequently, the stage of the coalescence in large-sized silicon single crystals begins at temperatures close to the temperatures of the formation of clusters of intrinsic point defects (depending on the thermal growth conditions, these are microvoids or dislocation loops).

The absorption of vacancies by growing oxygen precipitates results in the emission of silicon atoms in interstitial sites. In turn, the intrinsic interstitial silicon atoms interact with growing carbon precipitates, which, in the course of their growth, supply vacancies for growing oxygen precipitates. This interplay between the processes leads to an accelerated changeover of the subsystems of oxygen and carbon precipitates to the stage of the coalescence as compared to the independent evolution of these two subsystems. The change in the thermal conditions for the growth of small-sized FZ-Si single crystals (high growth rates and axial temperature gradients) leads to the fact that the stage of the coalescence begins far in advance (at $T \approx T_{m}-20 K$ ). The results of theoretical calculations have demonstrated that a decrease in the concentrations of oxygen and carbon in small-sized single crystals leads to a further decrease in the time of occurrence of the growth stage of precipitates. The change in thermal conditions of crystal growth (in particular, an increase in the growth rate and in the axial temperature gradient in the crystal) substantially affects the stage of the growth of precipitates. In turn, the decrease in the time of occurrence of the growth stage of precipitates is associated, to a lesser extent, with the decrease in the concentration of impurities in crystals. Eventually, these factors are responsible for the decrease in the average size of the precipitates.

The kinetic model of growth and coalescence of oxygen and carbon precipitates in combination with the kinetic models describing their formation represents a unified model of the process of precipitation in dislocation-free silicon single crystals.

\section{Diffusion kinetic of formation of the microvoids and dislocation loops}

As mentioned earlier the defect formation processes in a semiconductor crystal, in general, and in silicon, in particular, have been described using the model of point defect dynamics; in this case, the crystal has been considered a dynamic system and real boundary conditions have been specified. However, the model of point defect dynamics has not been used for calculating the formation of interstitial dislocation loops and microvoids under the 
assumption that the recombination of intrinsic point defects is absent in the vicinity of the crystallization front. This fact is evidenced by experimental and theoretical investigations (V.I. Talanin \& I.E. Talanin, 2006a, 2007a).

\subsection{Kinetics of formation of microvoids}

The experimentally determined temperature range of the formation of microvoids in crystals with a large diameter is $1403 . .1343 \mathrm{~K}$ (Kato et al., 1996; Itsumi, 2002). In this respect, the approximate calculations for the solution in terms of the model of point defect dynamics were performed at temperatures in the range $1403 \ldots 1073 \mathrm{~K}$. The computational model uses the classical theory of nucleation and formation of stable clusters and, in strict sense, represents the size distribution of clusters (microvoids) reasoning from the time process of their formation and previous history.

The calculations were carried out in the framework of the model of point defect dynamics, i.e., for the same crystals with the same parameters as in already the classical work on the simulation of microvoids and interstitial dislocation loops (A-microdefects) (Kulkarni et al., 2004). According to the analysis of the modern temperature fields used when growing crystals by the Czochralski method, the temperature gradient was taken to be $G=2.5 \mathrm{~K} / \mathrm{mm}$ (Kulkarni et al., 2004). The simulation was performed for crystals $150 \mathrm{~mm}$ in diameter, which were grown at the rates $V_{g}=0.6$ and $0.7 \mathrm{~mm} / \mathrm{min}$. These growth conditions correspond to the growth parameter $V_{g} / G>\xi_{\text {crit. }}$.

Detailed calculations are presented in the articles (V.I. Talanin \& I.E. Talanin, 2010b).Our results somewhat differ from those obtained in (Kulkarni et al., 2004). These differences are as follows: (i) the nucleation rate of microvoids at the initial stage of their formation is low and weakly increases with a decrease in the temperature and (ii) a sharp increase in the nucleation rate, which determines the nucleation temperature, occurs at a temperature $\mathrm{T} \sim$ $1333 \mathrm{~K}$. These differences result from the fact that the recombination factor in our calculations was taken to be $k_{I V}=0$. For $k_{I V} \neq 0$, consideration of the interaction between impurities and intrinsic point defects in the high-temperature range becomes impossible, which is accepted by the authors of the model of point defect dynamics (Kulkarni et al., 2004). In this case, in terms of the model, there arises a contradiction between the calculations using the mathematical model and the real physical system, which manifests itself in the ignoring of the precipitation process (Kulkarni et al., 2004).

\subsection{Kinetics of formation of dislocation loops (A-microdefects)}

The computational experiment was performed similarly to the calculations of the formation of microvoids. The simulation was performed for crystals $150 \mathrm{~mm}$ in diameter, which were grown at the rates $V_{g}=0.10$ and $0.25 \mathrm{~mm} / \mathrm{min}$ for the temperature gradient $G=2.5 \mathrm{~K} / \mathrm{mm}$. These growth conditions correspond to the growth parameter $V_{g} / G<\xi_{\text {crit. }}$.

Detailed calculations are presented in the articles (V.I. Talanin \& I.E. Talanin, 2010b). The temperature of the formation of A-microdefects corresponds to $1153 \mathrm{~K}$. An increase in the crystal growth rate weakly decreases the critical radius of A-microdefects and slightly affects the nucleation temperature. An increase in the crystal growth rate leads to an almost twofold decrease in the concentration of introduced defects. 
The data of the computational experiment on the determination of the microvoid concentration correlate well with the experimentally observed results $\left(\begin{array}{llll}10^{4} & \ldots & 10^{5} \mathrm{~cm}^{-3}\end{array}\right)$ (Itsumi, 2002). For the A-microdefects, for which the concentration according to the experimental data is $\sim 10^{6} \ldots 10^{7} \mathrm{~cm}^{-3}$ (Petroff \& Kock, 1975; Foll \& Kolbesen, 1975), the discrepancy is as large as three orders of magnitude. This can be explained by the fact that, unlike microvoids, which are formed only through the coagulation mechanism, the formation of A-microdefects occurs according to both the coagulation mechanism and the mechanism of prismatic extrusion (deformation mechanism) (V.I. Talanin \& I.E. Talanin, 2006a). The results of the calculations suggest that the main contribution to the formation of A-microdefects is made by the mechanism of prismatic extrusion when the formation of interstitial dislocation loops is associated with the relieving of stresses around the growing precipitate. Consequently, the impurity precipitation processes that proceed during cooling of the crystal from the crystallization temperature are fundamental (primary) in character and determine the overall defect formation process in the growth of dislocation-free silicon single crystals.

The calculations of the formation of microvoids and dislocation loops (A-microdefects) demonstrated that the above assumptions do not lead to substantial differences from the results of the previous calculations in terms of the model of point defect dynamics. This circumstance indicates that the mathematical model of point defect dynamics can be adequately used on the basis of the physical model in which the impurity precipitation process occurs before the formation of microvoids or interstitial dislocation loops. Moreover, the significant result of the calculations is the confirmation of the coagulation mechanism of the formation of microvoids and the deformation mechanism of the formation of interstitial dislocation loops. Therefore the model of the dynamics of point defects can be considered as component part of the diffusion model for formation grown-in microdefects.

\subsection{Model of the vacancy coalescence}

Model vacancy coalescence is a simplified model for the analysis of individual parameters of process of the formation microvoids. Detailed calculations are presented in the articles (V.I. Talanin \& I.E. Talanin, 2010c). The fundamental interaction between impurities and intrinsic point defects upon crystal cooling under certain thermal conditions $(T<1423 \mathrm{~K}$ ) leads to impurity depletion and the formation of a supersaturated solid solution of intrinsic point defects. The decay of this supersaturated solid solution causes the coagulation of intrinsic point defects in the form of microvoids.

An analysis of the experimental and calculated data within model of the vacancion coalescence in accordance with the heterogeneous diffusion model of the formation of grown-in microdefects revealed the following reasons for the occurrence of microvoids in dislocation-free silicon single crystals: (i) a sharp decrease in the concentration of background impurity that was not associated into impurity agglomerates (formed in the cooling range of $1683 . .1423 \mathrm{~K}$ ); (ii) a large (over $80 \mathrm{~mm}$ ) crystal diameter (in this case vacancies fail to drain from the central part of the crystal to the lateral surface); (iii) crystals of large diameter generally contain a ring of D-microdefects which forms due to the emergence of the (111) face on the crystallization front and which depletes the region inside with impurity atoms. 
The growth parameter $V_{g} / G$ describes the fundamental reasons related to the systematic nonuniform impurity distribution during crystal growth from a melt. Based on an analysis of the experimental results, one can suggest that the parameter $V_{g} / G$ controls the growth because it describes the condition for the emergence of the (111) face at the crystallization front. Therefore, the impurity depletion inside the ring of D-microdefects upon crystal cooling at $T<1423 \mathrm{~K}$ is caused by two things: the impurity bonding during the formation of primary grown-in microdefects $((\mathrm{I}+\mathrm{V})$-microdefects) and the impurity drift to the (111) face, which is equivalent to the annular distribution of primary D-type grown-in microdefects. In this case, excess vacancies arise within the ring of D-microdefects to form a supersaturated solid solution with its subsequent decay and the formation of vacancy microvoids. In contrast, excess silicon self-interstitials arise beyond the D-ring to form a supersaturated solid solution with its subsequent decay and the formation of interstitial dislocation loops (A-microdefects) (V.I. Talanin \& I.E. Talanin, 2010c).

The experimental classification of grown-in microdefects employs the terms such as Amicrodefects, B-microdefects, $\mathrm{D}(\mathrm{C})$-microdefects, (I+V)-microdefects and microvoids (V.I. Talanin \& I.E. Talanin, 2006a). It was found that A-microdefects constitute interstitial-type dislocation loops, and B-microdefects, $\mathrm{D}(\mathrm{C})$-microdefects, (I+V)-microdefects constitute precipitates of background oxygen and carbon impurities at different stages of their evolution (V.I. Talanin \& I.E. Talanin, 2006a; V.I. Talanin \& I.E. Talanin, 2011a)). At present, it is difficult to apply the experimental classification, since it is necessary to interpret the terms of every type of the grown-in microdefects for each publication. At the same time, from the physical point of view there are only three types of grown-in microdefects, i.e. impurity precipitates, dislocation loops and microvoids. Besides, when considering the formation of defects in silicon after processing (post-growth microdefects) the terms such as precipitates, dislocation loops and microvoids are also employed. Therefore, in order to harmonize a defect structure, we propose to switch to the physical classification of grown-in microdefects (V.I. Talanin \& I.E. Talanin, 2004).

\subsection{Kinetic model for the formation and growth of dislocation loops}

Kinetics of high-temperature precipitation involves three stages: (i) the nucleation of a new phase, (ii) the growth stage and (iii) the stage coalescence. Precipitates originate from elastic interaction between point defects. They are, initially, present in coherent, elastic and deformable state, when lattice distortions close to the precipitate-matrix boundary are not large, and one atom of the precipitate corresponds to one atom of the matrix (Goldstein et al., 2011). Elastic deformations and any mechanical stress connected with them cause a transfer of excessive (deficient) substance from the precipitate or vice versa. Storage of elastic strain energy during the precipitate growth results in a loss of coherence by matrix. In this case it is impossible to establish one-to-one correspondence between atoms at different sides of the boundary. It results in structural relaxation of precipitates which occurs due to formation and movement of dislocation loops.

To simulate a stress state of the precipitate and the matrix surrounding it, it is sufficient to observe the precipitate which is simple spherical in shape. There can be found analytical solutions in respect of spherical precipitates (Kolesnikova \& Romanov, 2004). Let us take the theoretical and experimental researches of stress relaxation at volume quantum dots 
as initial model (Chaldyshev et al., 2002; Kolesnikova \& Romanov, 2004; Chaldyshev et al., 2005; Kolesnikova et al., 2007). According to these representations, as far as the precipitate grows, its elastic field induces the formation of a circular interstitial dislocation loop of mismatch. This process contributes to the decrease in total strain energy of the system. A growing precipitate displaces the matrix material in the crystal volume. Interstitial atoms form an interstitial dislocation loop near to the precipitate. At the same time, a mismatch dislocation loop is formed on the very precipitate (Kolesnikova et al., 2007). At the same time, the critical sizes of precipitates, at which formation of dislocations is energy favorable, have the same order as the critical size of dislocation loops (Kolesnikova et al., 2007).

In the volume of silicon the precipitate produces a stress field caused by mismatch between the lattice parameters of precipitate $\left(a_{1}\right)$ and the surrounding matrix $\left(a_{2}\right)$ (Kolesnikova et al., 2007). Then, the intrinsic deformation of the precipitate is defined as described bellow

$$
\varepsilon=\frac{a_{1}-a_{2}}{a_{1}}
$$

In general, the precipitate intrinsic deformation in the matrix volume can be expressed as follows

$$
\varepsilon^{*}=\left(\begin{array}{lll}
\varepsilon_{x x} & \varepsilon_{x y} & \varepsilon_{x z} \\
\varepsilon_{x y} & \varepsilon_{y y} & \varepsilon_{y z} \\
\varepsilon_{z x} & \varepsilon_{z y} & \varepsilon_{z z}
\end{array}\right) \delta\left(\Omega_{p r}\right)
$$

where the diagonal terms constitute a dilatation mismatch between the precipitate and matrix lattices; the other terms are shear components; $\delta\left(\Omega_{p r}\right)$ is the Kronecker symbol. Elastic fields of precipitate (stresses $\sigma_{i j}$ and deformation $\varepsilon_{i j}$ ) and field of full displacements are calculated taking into account their own deformation (3) and region of localization of the precipitate $\delta\left(\Omega_{p r}\right)$. The calculation of elastic fields of the precipitate is carried out by wellknown scheme by using the elastic modules, Green's function of an elastic medium or its Fourier transform (Kolesnikova \& Romanov, 2004).

Consider the simplest model of a spherical precipitate with equiaxed own deformation $\varepsilon_{i i}^{*}=\varepsilon, \varepsilon_{i j}^{*}=0(i \neq j ; i, j,=x, y, z)$. The elastic strain energy of spheroidal defect with increasing radius of precipitate $\left(R_{p r}\right)$ increases as a cubic law (Kolesnikova et al., 2007):

$$
E_{p r}=\frac{32 \cdot \pi}{45 \cdot(1-v)} \cdot J \cdot \varepsilon^{2} \cdot R_{p r}^{3}
$$

where $J$ is the shear modulus; $v$ is the Poisson's ratio. From a certain critical radius $R_{\text {crit }}$ takes effect mechanism for resetting the elastic energy of the precipitate. This mechanism leads to the formation of circular interstitial dislocation loop. Energy criterion of this mechanism is the condition $E^{\text {initial }} \geq E^{\text {final }}$, here $E^{\text {initial }}, E^{\text {final }}$ is the elastic energy of the system with the precipitate before and after relaxation, respectively (Kolesnikova et al., 2007). 
In respect of a spherical precipitate with equiaxial intrinsic deformation, the calculation of elastic fields of the precipitate is substantially simplified. Let us assume that the intrinsic elastic strain energy of the precipitate before and after the formation of a dislocation loop of mismatch remains constant $E_{p r}^{\text {initial }}=E_{p r}^{\text {final }}$. Then the criterion of nucleation loop of misfit dislocation can be represented by the condition $0 \geq E_{D}+E_{p r D}$, where $E_{D}$ is the energy of loop of misfit dislocation; $E_{p r D}$ is the energy of interaction of precipitate with the dislocation loop (Kolesnikova et al., 2007).

To estimate believe that loop of misfit dislocation is the equatorial location on the spheroidal precipitate $R_{D}=R_{p r}$ the self-energy prismatic loop (Kolesnikova et al., 2007)

$$
E_{\text {loop }}=\frac{J \cdot b^{2} \cdot R_{D}}{2 \cdot(1-v)} \cdot\left(\ln \frac{2 \cdot R_{D}}{f}-2\right)
$$

where $f$ is the radius of the core loop; $b$ is the magnitude of the Burgers vector. The critical radius of precipitate for the formation of dislocation loop is determined from the expression (Kolesnikova et al., 2007)

$$
R_{c r i t}=\frac{3 b}{8 \pi(1+v) \varepsilon}\left(\ln \frac{1.08 \alpha R_{\text {crit }}}{b}\right)
$$

where $\alpha$ is a constant contribution of the dislocation core. Expression (6) is approximate and can only be used to determine the value critical radius $R_{\text {crit }}$.

This paper (Bonafos et al., 1998) theoretically considers the increase kinetics for dislocation loops at the stages of loop growth and coalescence. It is assumed that, in general, the growth is either controlled by energy barrier when atom is captured by the loop, or by activation energy of interstitial atom diffusion. In conditions of cooling the crystal after being grown, we presume that the diffusion processes play a core role. The model (Burton \& Speight, 1985) is further used in the calculations for evolution in size-dependant distribution of loops and for evolution in loop density.

The dislocation loops with a radius of $R>R_{\text {crit }}$ become bigger in size at the coalescence stage, while small dislocation loops with a radius of $R<R_{\text {crit }}$ will dissolve (Bonafos et al., 1998; Burton \& Speight, 1985). The growth of dislocation loops during cooling after the growth of single crystal silicon occurs as due to dissolution of small loops with sizes less than critical, and as a result supersaturation for intrinsic interstitial silicon atoms. In this case, the crystal growth ratio is $V_{g} / G<\xi_{\text {crit }}$. When oversaturation of vacancies $\left(V_{g} / G>\xi_{\text {crit }}\right.$ ) occurs, the interstitial dislocation loops start to dissolve. Increase in the radius of interstitial dislocation loop can be defined by the formula depending on the crystal cooling time (Burton \& Speight, 1985):

$$
R(t)=\sqrt{R_{c r i t}^{2}+j \cdot D(t) \cdot t}
$$


where $D(t)$ is the diffusion coefficient of intrinsic interstitial silicon atoms; $t$ is the time cooling the crystal; $j$ is the proportionality factor. The value of the cooling time of the crystal is determined from the dependence: $T(t)=\frac{T_{m}^{2}}{T_{m}+U \cdot t}$, where $T_{m}$ is the crystallization temperature (melting) of silicon; $U=V_{g} \cdot G$ is the cooling rate of the crystal. The loop concentration depends on the crystal cooling time (Burton \& Speight, 1985):

$$
N(t)=\frac{M(t)}{1+D(t) \cdot t / 2 \cdot R_{c r i t}^{2}}
$$

where $M(t)$ is the concentration of precipitates.

Initially, the precipitates act as stoppers for the dislocation loops restraining their distribution and generation. Then, the precipitates facilitate the formation of dislocation loops due to the action of Bardeen-Herring or Frank-Read sources (Gyseva et al., 1986). These processes lead to the formation and growth of complex dislocation loops. Formation and development of dislocation loops caused by the high-temperature precipitation of background impurities (oxygen and carbon). Growth and coalescence of dislocation loops are generally maintained due to the generation of growing precipitates instead of silicon self-interstitials, and as well to the dissolution of small dislocation loops.

If the parameter of crystal growth $V_{g} / G<\xi_{c r i t}$, for stress relaxation precipitate generates interstitial silicon atoms. If the parameter of crystal growth $V_{g} / G>\xi_{\text {crit }}$, for stress relaxation precipitate adsorbs vacancies. In this case is suppressed the formation of dislocation loops.

\section{Construction of the defect structure of dislocation-free silicon single crystal and device structures on their base}

Experimental studies require large material and time costs, while theoretical studies are carried out for single crystals with selected fixed parameters of their growth. It is necessary to develop a new method for studying the defect structure of silicon without these drawbacks. In the diffusion model of formation grown-in microdefects all the parameters of precipitates, microvoids and dislocation loops are determined through the thermal conditions of growth. Therefore, definition the type of defect structure and calculation of the formation of microdefects is conducted depending on the values of crystal growth rate, temperature gradients and cooling rate of the crystal. On this basis, we have developed a new method for studying the defect structure of silicon. This method allows to simulate a real experiment by the software (V.I. Talanin et. al., 2011b).

Electronic equivalent of an object for direct test on the computer are programs that converted the mathematical models and algorithms to the available computer language $(\mathrm{C}++)$. The program is written high-level language programming in $\mathrm{C}++$ compiler Borland $\mathrm{C}++$ Builder. Program complex consists of two consecutive parts: (i) the unit determination the type of defect structure and (ii) the unit of calculation and graphs. 
At the stage of determining the type of the structure defect of software system works as follows. Initially is the choice of method of growing dislocation-free silicon single crystals (Czochralski method or the floating-zone method) and then is the choice of certain diameter of the crystal. The ratio of $V_{\text {gcrit }} / G=\xi$ theoretically and experimentally determined in a certain range of values $\left(0.06 \mathrm{~mm}^{2} / \mathrm{K} \min \leq \xi \leq 0.3 \mathrm{~mm}^{2} / \mathrm{K} \mathrm{min}\right)$. Therefore, we choose the certain value $\xi$ for the calculation. For a given diameter in a certain range of values are selected: the value of the axial temperature gradient in the center of the crystal $\left(G_{a}\right)$ and the value of the minimum $\left(V_{\min }\right)$ and maximum $\left(V_{\max }\right)$ crystal growth rate. These values are determined from the analysis of experimental and theoretical data for different diameters of the crystal. Then produced choice of the axial temperature gradient at the edge of the crystal $\left(G_{e}\right)$ in the range $G_{e} / G_{a}=1.0 \ldots 2.5$. The reliability and accuracy of the computational experiments can be experimentally verified by means of selective etching crystal of the plane which passes through the center of the crystal and parallel to the direction of growth. In case of deviations can by using of the selection of parameters $G_{a}, G_{e}, \xi$ achieve full compliance with theoretical and experimental data. In addition, this technique avoids the difficulties of experimental determination of the $G_{a}$ and $G_{e}$, especially for large diameter crystals (V.I. Talanin et. al., 2011b). At the last stage of determining the type of defect structure on the resulting dependence of the critical growth rate $V_{g c r i t}(r)=\xi \cdot G(r)$ is imposed value of real crystal growth rate $V=$ const (Fig. 2). This procedure allows determining the type of defect structure of a real crystal. Depending on the position of the line $V=$ const relative to the curve $V_{\text {gcrit }}(r)=\xi \cdot G(r)$ may be three areas of the defect structure. Calculation of these areas produced the block of calculation and graphs (Fig. 3).

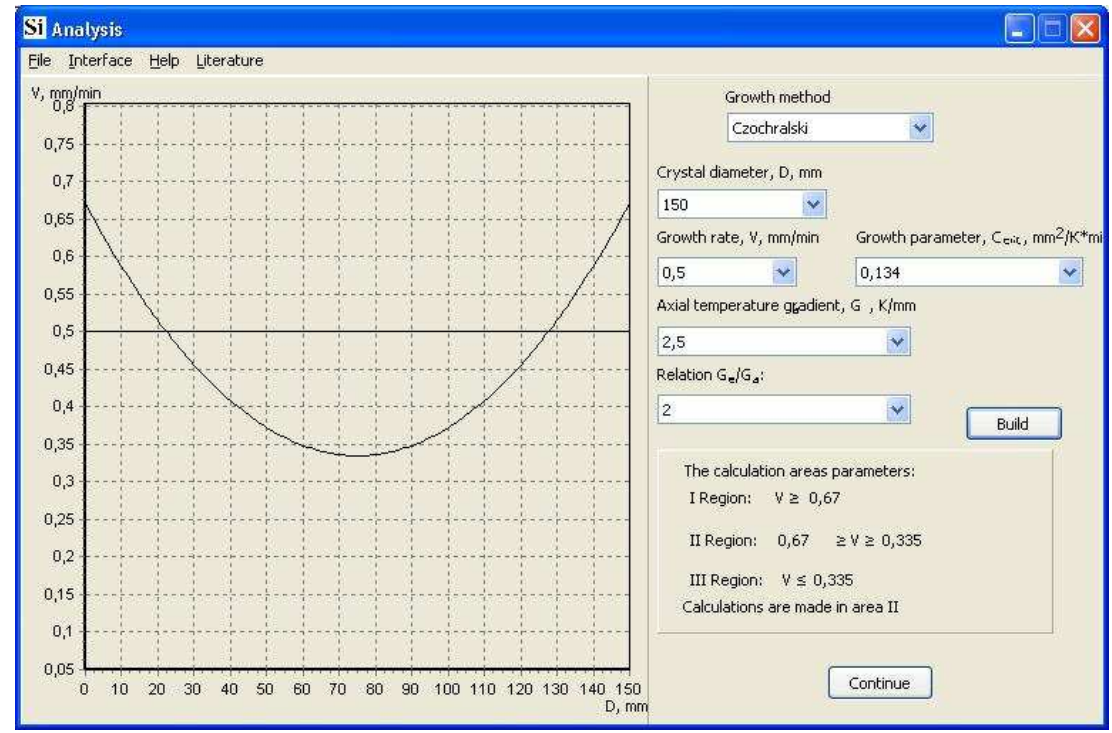

Fig. 2. Shape analysis of the defect structure 
The first area of the calculation is characterized by high rates of crystal growth, when the above V-shaped distribution of precipitates formed only microvoids and precipitates. The second area of calculation is characterized by the average growth rate of the crystal, when a ring of precipitate in the plane perpendicular to the direction of growth crystal is formed. In this case inside the ring are formed precipitates and microvoids, outside the ring are formed precipitates and interstitial dislocation loops. The third area of calculation is characterized by low rates of crystal growth, when the below V-shaped distribution of precipitates are formed precipitates and interstitial dislocation loops. Calculation of the precipitates is carried out within the classical theory of nucleation, growth and coalescence of precipitates by means of the analytical and approximate calculations. Critical radius of precipitates, the distribution of precipitates in size, change in the average size of precipitates during the cooling of the crystal, and other parameters of the precipitation of carbon and oxygen are determined (Fig. 3). Mathematical models and calculation parameters are given in (V.I. Talanin et al., 2008; V.I. Talanin \& I.E. Talanin, 2010a; 2011a). When calculating the vacancy microvoids initially are tested of conditions their formation, since microvoids are not formed at a cooling rate of the crystal $V_{\text {cool }} \geq 40 \mathrm{~K} / \mathrm{min}$ (Nakamura et al., 2002) and in crystals with a diameter less than 70 $\mathrm{mm}$ (V.I. Talanin et al., 2010c). Calculation of the microvoids and interstitial dislocation loops to determines for each of these types of defects such parameters as the critical radii and the concentrations (V.I. Talanin \& I.E. Talanin, 2010b).

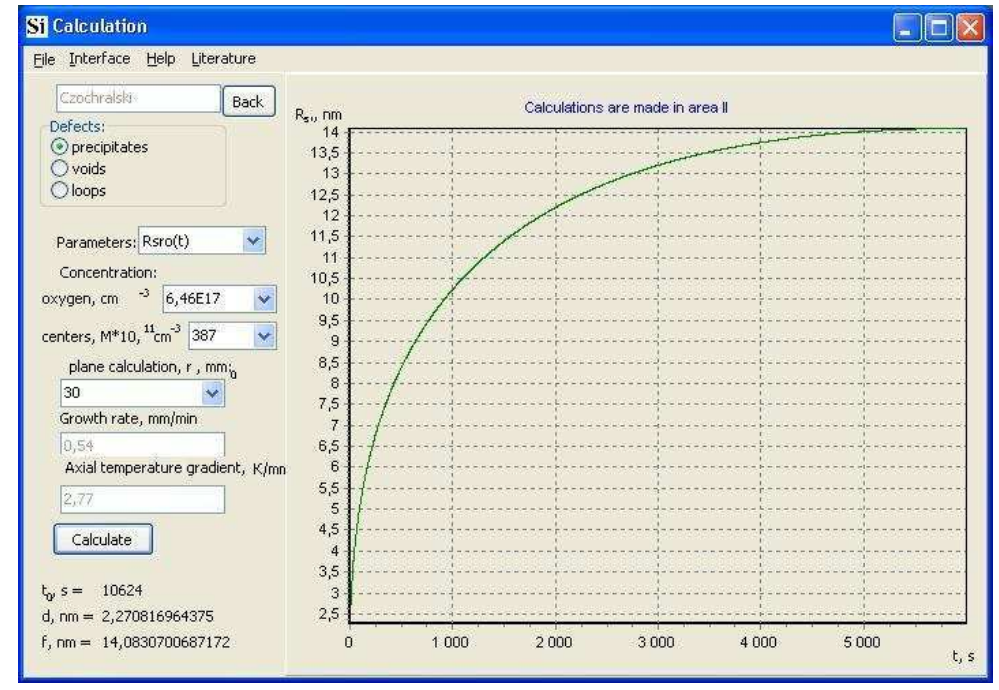

Fig. 3. Form of calculation of the defect structure

The software complex performs imitation of a real experiment and with the maximum precision reproduces the thermal characteristics of silicon single crystal growing. The software complex allows to determine the thermal conditions of crystal growth, to predict and control the defect structure of the crystal. Calculations formations of grown-in microdefects are in good agreement with the experimental results of research (V.I. Talanin et. al., 2011b). 
The program complex is the first experience of a virtual experimental device for research the real structure of dislocation-free silicon single crystals. Currently, it can be used for the analysis and calculation of the defect structure of undoped single-crystal silicon. Depending on the thermal conditions of crystal growth can determine crucial parameters such as size and concentration of grown-in microdefects. Approach to the analysis and calculation of formation grown-in microdefects has an important advantage in simplicity, accessibility and sufficient adequacy of mathematical modeling in comparison with other methods. For its implementation does not require supercomputers, and can effectively use the experimental data, experience and intuition of physicists, materials scientists and technologists for the analytical calculation and design of the defect structure. The program complex is easy to implement on a personal computer in technology and research practices.

Disadvantages software system is determined deficiencies of the diffusion model of formation grown-in microdefects. These include: (i) one-dimensional model; (ii) failure to account for the width of the V-shaped distribution of precipitates; (iii) uncertainty in determining of thermal conditions of growth; (iv) the error of approximate numerical methods. Elimination of these deficiencies will increase the accuracy of the calculations.

The influence of other impurities (e.g., dopants, nitrogen, hydrogen, iron, and others) on the formation of the defect structure of silicon can be taken into account by using two approaches: a rigorous approach and a simplified approach. A rigorous approach requires accurate accounting of all the components in equations (1) mass balance of point defects in the crystal. In this case, the solution of the corresponding system of coupled equations of the Fokker-Planck equation can be considerably more difficult.

A simplified approach assumes the separation of impurities in the two groups. The first group contains impurities, which interact with vacancies. The second group contains impurities, which interact with self-interstitial atoms. This interaction for the first group of impurities is similar to the interaction of oxygen atoms with vacancies. This interaction for the second group of impurities is similar to carbon atoms interaction with self-interstitial atoms.. Therefore, in equations (1) the sum of the concentrations of the components of the first group of impurities is equivalent to the impurity concentration of oxygen, and oxygen diffusion coefficient is the sum of the diffusion coefficients of the system components. Are defined analogously the components of interaction in the second group of impurities. Then the system of equations reduced to the system of equations (1), followed by the task of determining the chemical nature of precipitates.

The task of construction the defect structure of dislocation-free silicon single crystal is an inverse problem the analysis and calculation of grown-in microdefects. In this case, you must first specify the type, size and concentration of grown-in microdefects. Parameters of grown-in microdefects are selected based on the requirements for defect structure of devices and integrated circuits. In the next stage are calculated parameters of crystal growth (the growth rate for a certain diameter of the crystal and temperature gradients), which provide presence of given defects of structure. We get that the defect structure determines thermal conditions of crystal growth. To automate the process of crystal growth need to carry out the development of software products based on the diffusion model in combination with known software products for modelling crystal growth. 
Production technologies of devices based on silicon technology are connected with various impacts on the material. Heat treatments, ionizing radiations and mechanical effects have a critical impact on the initial defect structure of dislocation-free silicon single crystals. Technological impacts are lead to the transformation of grown-in microdefects. In the general case technological impacts are leads to: (i) the growth of initial grown-in microdefects; (ii) formation on grown-in microdefects of new defects (e.g., stacking faults); (iii) the formation of new defects. In contrast to grown-in microdefects these defects of crystal structure can be defined as postgrowth microdefects.

At the present time for the description of the formation of postgrowth microdefects are used a variety of models. Overview of the main models has been presented in (Sadamitsu et. al., 1993). The purpose of all models is to consider the formation and growth of defects as a result of technological impacts (e.g., by heating the crystal). A common deficiency of these models is the lack of consideration of the influence of grown-in microdefects, which are in the initial wafer.

Diffusion model of formation grown-in microdefects makes it possible to calculate of the defect structure of the initial silicon wafers. So from our point of view of theoretical analysis of the formation of postgrowth microdefects must be based on the diffusion model. It should be noted that taking into account all components of the general solution may be difficult. However, in some cases (e.g., heat treatment of silicon with a certain type of grown-in microdefects) can be solved in the near future. Building a general model for the formation of postgrowth microdefects will help optimize technological processes for production of devices. In this case, we can construct the defect structure of devices during their manufacture.

\section{Conclusion}

The diffusion model of the formation grown-in microdefects provides the unity and adequacy of physical and mathematical modeling. This model simulates of the defect structure of dislocation-free silicon single crystals of any diameters. The model of point defects dynamics can be considered as component of the diffusion model for formation grown-in microdefects. The diffusion model allowed to create software for personal computer. With the help of software can be conducted analytical researches which replace the expensive experimental researches.

Further development and modification of the software will lead to the development of information system of formation grown-in microdefects in dislocation-free silicon single crystals. The combinations of an information system with software for control the crystal growth will allow construct the defect structure of crystals during their growth. In turn, application a diffusion model of formation grown-in microdefects in the calculation of the formation of postgrowth microdefects allow to calculate the defect structure of silicon-based devices. In this case, it is possible to adequately construction the defect structure of silicon devices. We believe that the proposed in an article algorithm for the engineering of the defect structure of silicon can be used for other materials.

\section{References}

Ammon von, W.; Dornberger, E. \& Hansson P.O. (1999). Bulk properties of very large diameter silicon single crystal. Journal Crystal Growth, Vol. 198-199, No. 1-4, pp. 390398, ISSN 0022-0248. 
Bonafos, C.; Mathiot, D. \& Claverie A. (1998). Ostwald ripening of end-of-range defects in silicon. Journal of Applied Physics, Vol. 83, No. 6, pp. 3008-3018, ISSN 0021-8979.

Bulyarskii, S.V. \& Fistul, V.I. (1997). Thermodynamics and kinetics of interacting defects in semiconductors, Nauka, ISBN 5-02-015164-5, Moscow, Russia.

Burton, B. \& Speight M.V. (1985). The coarsening and annihilation kinetics of dislocation loops. Philosophical Magazine A, Vol. 53, No. 3, pp. 385-402, ISSN 0141-8610.

Chaldyshev, V.V.; Bert, N.A.; Romanov, A.E.; Suvorova, A.A.; Kolesnikova, A.L.; Preobrazhenskii, V.V.; Putyato, M.A.; Semyagin, B.R.; Werner, P.; Zakharov, N.D. \& Claveria, A. (2002). Local stresses induced by nanoscale As-Sb clusters in GaAs matrix. Applied Physics Letters, Vol. 80, No. 3, pp. 377-381, ISSN 0003-6951.

Chaldyshev, V.V.; Kolesnikova, A.L.; Bert, N.A. \& Romanov, A.E. (2005). Investigation of dislocation loops associated with As-Sb nanoclusters in GaAs. Journal of Applied Physics, Vol. 97, No. 2, pp. 024309-024319, ISSN 0021-8979.

Cho, H.-J.; Sim, B.-C. \& Lee, J.Y. (2006). Asymmetric distributions of grown-in microdefects in Czochralski silicon. Journal Crystal Growth, Vol. 289, No. 2, pp. 458-463, ISSN 0022-0248.

Dornberger, E.; Ammon, von W.; Virbulis, J.; Hanna, B. \& Sinno T. (2001). Modeling of transient point defect dynamics in Czochralski silicon crystal. Journal Crystal Growth, Vol. 230, No. 1-2, pp. 291-299, ISSN 0022-0248.

Föll, H. \& Kolbesen B.O. (1975). Formation and nature of swirl defects in silicon. Journal of Applied Physics, Vol. 8, No. 3, pp. 319-331, ISSN 0021-8979.

Goethem, van N.; Potter, de A.; Bogaert, van den N. \& Dupret, F. (2008). Dynamic prediction of point defects in Czochralski silicon growth. An attempt to reconcile experimental defect diffusion coefficients with the criterion V/G. Journal of Physics and Chemistry of Solids, Vol. 69, No. 2-3, pp. 320-324, ISSN 0022-3697.

Goldstein, R.V.; Mezhennyi, M.V.; Mil'vidskii, M.G.; Reznik, V.Ya.; Ustinov, K.B. \& Shushpannikov, P.S. (2011). Experimental and theoretical investigation of formation of the oxygen-containing precipitate-dislocation loop system in silicon. Physics of the Solid State, Vol. 53, No. 3, pp. 527-538, ISSN 1063-7834.

Gyseva, N.B.; Sheikhet, E.G.; Shpeizman, V.V. \& Shulpina I.L. (1986). Dislokazionnay aktivnost mikrodefektov v monokristalax kremnia. Fizika tverdogo tela, Vol. 28, No. 10, pp. 3192-3194, ISSN 0367-3294.

Huff, H.R. (2002). An electronics division retrospective (1952-2002) and future opportunities in the twenty-first century. Journal of the Electrochemical Society, Vol. 149, No. 5, pp. S35-S58, ISSN 0013-4651.

Itsumi, M. (2002). Octahedral void defects in Czochralski silicon. Journal Crystal Growth, Vol. 237-239, No. 3, pp. 1773-1778, ISSN 0022-0248.

Kato, M.; Yoshida, T.; Ikeda, Y. \& Kitagawara, Y. (1996). Transmission electron microscope observation of "IR scattering defects" in as-grown Czochralski Si crystals. Japanese Journal Applied Physics, Vol. 35, No. 11, pp. 5597-5601, ISSN 0021-4922.

Kock de, A.J.R. (1970). Vacancy clusters in dislocation-free silicon. Applied Physics Letters, Vol. 16, No. 3, pp. 100-102, ISSN 0003-6951.

Kock de, A.J.R.; Stacy, W.T. \& Wijgert van de, W.M. (1979). The effect of doping on microdefect formation in as-grown dislocation-free Czochralski silicon crystals. Applied Physics Letters, Vol. 34, No. 9, pp. 611-616, ISSN 0003-6951.

Kolesnikova, A.L. \& Romanov, A.E. (2004). Misfit dislocation loops and critical parameters of quantum dots and wires. Philosophical Magazine Letters, Vol. 84, No. 3, pp. 501506, ISSN 0950-0839. 
Kolesnikova, A.L.; Romanov, A.E. \& Chaldyshev V.V. (2007). Elastic-energy relaxation in heterostructures with strained nanoinclusions. Physics of the Solid State, Vol. 49, No. 4, pp. 667-674, ISSN 1063-7834.

Kulkarni, M.S.; Voronkov, V.V. \& Falster, R. (2004). Quantification of defect dynamics in unsteady-state and steady-state Czochralski growth of monocrystalline silicon. Journal Electrochemical Society, Vol. 151. - No. 5, pp. G663-G669, ISSN 0013-4651.

Kulkarni, M.S. (2005). A selective review of the quantification of defect dynamics in growing Czochralski silicon crystals. Ind. Eng. Chem. Res., Vol. 44, No. 16, pp. 6246-6263, ISSN 0888-5885.

Kulkarni, M.S. (2007). Defect dynamics in the presence of oxygen in growing Czochralski silicon crystals. Journal Crystal Growth, Vol. 303, No. 2, pp. 438-448, ISSN 0022-0248.

Kulkarni, M.S. (2008a). Lateral incorporation of vacancies in Czochralski silicon crystals. Journal Crystal Growth, Vol. 310, No. 13, pp. 3183-3191, ISSN 0022-0248.

Kulkarni, M.S. (2008b). Defect dynamics in the presence of nitrogen in growing Czochralski silicon crystals. Journal Crystal Growth, Vol. 310, No. 2, pp. 324-335, ISSN 0022-0248.

Nakamura, K.; Saishoji, T. \& Tomioka, J. (2002). Grown-in defects in silicon crystals. Journal Crystal Growth, Vol. 237-239, No. 1-4, pp. 1678-1684, ISSN 0022-0248.

Petroff, P.M. \& Kock de, A.J.R. (1975). Characterization of swirl defects in floating-zone silicon crystals. Journal Crystal Growth, Vol. 30, No. 1, pp. 117-124, ISSN 0022-0248.

Prostomolotov, A.I. \& Verezub, N.A. (2009). Simplistic approach for 2D grown-in microdefects modeling. Physica status solidi (c), Vol. 6, No. 8, pp. 1878-1881, ISSN 1610-1642.

Prostomolotov, A.I.; Verezub, N.A.; Mezhennii, M.V. \& Reznik, V.Ua. (2011). Thermal optimization of $\mathrm{CZ}$ bulk growth and wafer annealing for crystalline dislocation-free silicon. Journal of Crystal Growth, Vol. 318, No. 1, pp. 187-192, ISSN 0022-0248.

Sadamitsu, S.; Umeno, S.; Koike, Y.; Hourai, M.; Sumita, S. \& Shigematsu, T. (1993). Dislocations, precipitates and other defects in silicon crystals. Japanese Journal Applied Physics, Vol. 32, No. 9, pp. 3675-3679, ISSN 0021-4922.

Sinno, T. (1999). Modeling microdefect formation in Czochralski silicon. Journal Electrochemical Society, Vol. 146, No. 6, pp. 2300-2312, ISSN 0013-4651.

Sitnikova, A.A.; Sorokin, L.M.; Talanin, I.E.; Sheikhet, E.G. \& Falkevich E.S. (1984). Electronmicroscopic study of microdefects in silicon single crystals grown at high speed. Physica Status Solidi (a), Vol. 81, No. 2, pp. 433-439, ISSN 1862-6300.

Sitnikova, A.A.; Sorokin, L.M.; Talanin, I.E.; Sheikhet, E.G. \& Falkevich, E.S. (1985). Vacancy type microdefects in dislocation-free silicon single crystals. Physica Status Solidi (a), Vol. 90, No. 1, pp. K31-K35, ISSN 1862-6300.

Talanin, V.I.; Talanin, I.E. \& Levinson, D.I. (2002a). Physical model of paths of microdefects nucleation in dislocation-free single crystals float-zone silicon. Cryst. Res. $\mathcal{E}$ Technol., Vol. 37, No. 9, pp. 983-1011, ISSN 0232-1300.

Talanin, V.I.; Talanin, I.E. \& Levinson, D.I. (2002b). Physics of the formation of microdefects in dislocation-free monocrystals of float-zone silicon. Semicond. Sci. Cryst. Res. $\mathcal{E}$ Technol., Vol. 17, No. 2, pp. 104-113, ISSN 0268-1242.

Talanin, V.I. \& Talanin, I.E. (2003). Physical nature of grown-in microdefects in Czochralskigrown silicon and their transformation during various technological effects . Physica Status Solidi (a), Vol. 200, No. 2, pp. 297-306, ISSN 1862-6300.

Talanin, V.I. \& Talanin, I.E. (2004). Mechanism of formation and physical classification of the grown-in microdefects in semiconductor silicon. Defect $\mathcal{E}$ Diffusion Forum, Vol. 230232, No. 1, pp. 177-198, ISSN 1012-0386. 
Talanin, V.I. \& Talanin, I.E. (2006a). Formation of grown-in microdefects in dislocation-free silicon monocrystals, In: New research on semiconductors, T.B. Elliot,(Ed.), 31-67, Nova Science Publishers, Inc., ISBN 1-59454-920-6, New York, USA.

Talanin, V.I. \& Talanin, I.E. (2006b). On the formation of vacancy microdefects in dislocation-free silicon single crystals. Ukranian Journal of Physics, Vol. 51, No. 11-12, pp. 108-112, ISSN 0503-1265.

Talanin, V.I. \& Talanin, I.E. (2007a). On the recombination of intrinsic point defects in dislocation-free silicon single crystals. Physics of the Solid State, Vol. 49, No. 3, pp. 467-470, ISSN 1063-7834.

Talanin, V.I.; Talanin, I.E. \& Voronin, A.A. (2007b). About formation of grown-in microdefects in dislocation-free silicon single crystals. Canadian Journal of Physics, Vol. 85, No. 12, pp. 1459-1471, ISSN 1208-6045.

Talanin, V.I.; Talanin, I.E. \& Voronin A.A. (2008). Modeling of the defect structure in dislocation-free silicon single crystals. Crystallography Reports, Vol. 53, № 7, pp. 1124-1132, ISSN 1063-7745.

Talanin, V.I. \& Talanin, I.E. (2010a). Kinetic of high-temperature precipitation in dislocationfree silicon single crystals. Physics of the Solid State, Vol. 52, No. 10, pp. 2063-2069, ISSN 1063-7834.

Talanin, V.I. \& Talanin, I.E. (2010b). Kinetics of formation of vacancy microvoids and interstitial dislocation loops in dislocation-free silicon single crystals. Physics of Solid State, Vol. 52, No. 9, pp. 1880-1886, ISSN 1063-7834.

Talanin, V.I. \& Talanin, I.E. (2010c). Modeling of defect formation processes in dislocationfree silicon single crystals. Crystallography Reports, Vol. 55, No. 4, pp. 675-681, ISSN 1063-7745.

Talanin, V.I. \& Talanin, I.E. (2011a). Kinetic model of growth and coalescence of oxygen and carbon precipitates during cooling of as-grown silicon crystals. Physics of the Solid State, Vol. 53, No. 1, pp. 119-126, ISSN 1063-7834.

Talanin, V.I.; Talanin, I.E. \& Ustimenko N.Ph. (2011b). A new method for research of grownin microdefects in dislocation-free silicon single crystals. Journal of Crystallization Process \& Technologys, Vol.1, № 2, pp. 13-17, ISSN 2161-7678.

Yang, D.; Chen, J.; Ma, X. \& Que, D. (2009). Impurity engineering of Czochralski silicon used for ultra large-scaled-integrated circuits. Journal Crystal Growth, Vol. 311, No. 3, pp. 837-841, ISSN 0022-0248.

Vas'kin, V.V. \& Uskov V.A. (1968). Vlianie kompleksoobrazovania na diffyziu primesei v polyprovodnikax. Fizika Tverdogo Tela, Vol. 10, No. 6, pp. 1239-1241, ISSN 0367-3294.

Veselovskaya, N.V.; Sheikhet, E.G.; Neimark, K.N. \& Falkevich, E.S. (1977). Defecty tipa klasterov v kremnii. Proceedings of IV simposiuma Rost i legirovanie polyprovodnikovyx kristalov i plenok, Vol. 2, pp. 284-288, Novosibirsk, USSR, June 1975.

Voronkov, V.V. \& Falster, R. (1998). Vacancy-type microdefect formation in Czochralski silicon. Journal Crystal Growth, Vol. 194, No.1, pp. 76-88, ISSN 0022-0248.

Voronkov, V.V. (2008). Grown-in defects in silicon produced by agglomeration of vacancies and self-interstitial. Journal Crystal Growth, Vol. 310, No. 7-9, pp. 1307-1314, ISSN 0022-0248.

Voronkov, V.V.; Dai B. \& Kulkarni M.S. (2011). Fundamentals and engineering of the Czochralski growth of semiconductor silicon crystals. Comprehensive Semiconductor science and Technology, Vol. 3, pp. 81-169, ISBN 978-0-444-53153-7.

Wang, Z. \& Brown, R.A. (2001). Simulation of almost defect-free silicon crystal growth. Journal Crystal Growth, Vol. 231, No. 2, pp. 442-452, ISSN 0022-0248. 


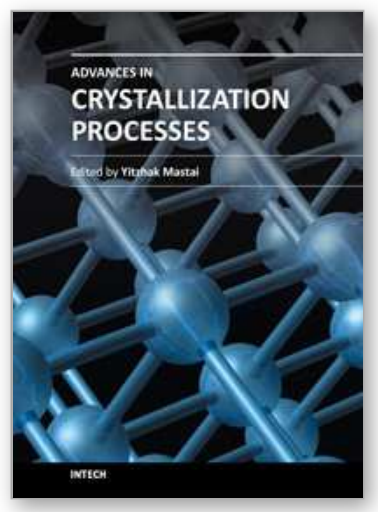

\section{Advances in Crystallization Processes}

Edited by Dr. Yitzhak Mastai

ISBN 978-953-51-0581-7

Hard cover, 648 pages

Publisher InTech

Published online 27, April, 2012

Published in print edition April, 2012

Crystallization is used at some stage in nearly all process industries as a method of production, purification or recovery of solid materials. In recent years, a number of new applications have also come to rely on crystallization processes such as the crystallization of nano and amorphous materials. The articles for this book have been contributed by the most respected researchers in this area and cover the frontier areas of research and developments in crystallization processes. Divided into five parts this book provides the latest research developments in many aspects of crystallization including: chiral crystallization, crystallization of nanomaterials and the crystallization of amorphous and glassy materials. This book is of interest to both fundamental research and also to practicing scientists and will prove invaluable to all chemical engineers and industrial chemists in the process industries as well as crystallization workers and students in industry and academia.

\section{How to reference}

In order to correctly reference this scholarly work, feel free to copy and paste the following:

V. I. Talanin and I. E. Talanin (2012). The Diffusion Model of Grown-In Microdefects Formation During Crystallization of Dislocation-Free Silicon Single Crystals, Advances in Crystallization Processes, Dr. Yitzhak Mastai (Ed.), ISBN: 978-953-51-0581-7, InTech, Available from: http://www.intechopen.com/books/advancesin-crystallization-processes/the-diffusion-model-of-grown-in-microdefects-formation-during-crystallization-ofdislocation-free-si

\section{INTECH}

open science | open minds

\section{InTech Europe}

University Campus STeP Ri

Slavka Krautzeka 83/A

51000 Rijeka, Croatia

Phone: +385 (51) 770447

Fax: +385 (51) 686166

www.intechopen.com

\section{InTech China}

Unit 405, Office Block, Hotel Equatorial Shanghai

No.65, Yan An Road (West), Shanghai, 200040, China

中国上海市延安西路65号上海国际贵都大饭店办公楼405单元

Phone: +86-21-62489820

Fax: $+86-21-62489821$ 
(C) 2012 The Author(s). Licensee IntechOpen. This is an open access article distributed under the terms of the Creative Commons Attribution 3.0 License, which permits unrestricted use, distribution, and reproduction in any medium, provided the original work is properly cited. 